SHORT REPORT

\title{
Many referrals under Dutch short stature guidelines
}

\author{
S van Buuren, D J A Bonnemaijer-Kerckhoffs, F K Grote, J M Wit, P H Verkerk
}

Arch Dis Child 2004;89:351-352. doi: 10.1136/adc.2003.038208

The number of referrals under strict adherence to the Dutch consensus guidelines for short stature was estimated using longitudinal data from 970 children (0-10 years). Results showed that over $38 \%$ of all children would have to be referred one or more times. There is therefore a clear need to revise the current guidelines.

A few years ago the Dutch Institute for Health Care Improvement published Consensus Guidelines for promoting early diagnosis and treatment of short stature. ${ }^{1}$ It was expected that use of these guidelines would lead to approximately 2500 referrals per year from the regular child health care system to a paediatrician. There was, however, little evidence that could back up this estimate.

\section{PARTICIPANTS, METHODS, AND RESULTS}

The guidelines introduced six screening rules based on height standard deviation scores (HSDS). Boys younger than 10 years and girls younger than 9 years ought to be referred if:

I. HSDS is lower than -2.5

II. HSDS is lower than -1.3 and HSDS is 1.3 lower than the target height SDS

III. The growth curve deflects by more than 0.25 SDS per year

IV. HSDS decreases by more than I SDS over several years

V. In children born small for dates (birth length SDS lower than -1.88$)$ HSDS is lower than -1.88 after the age of 2

VI. HSDS is lower than -1.3 and the child has disproportion or dysmorphic features.

Table 1 provides the precise description and the age range of each rule. These rules should be checked at each visit. A child should be referred if one or more rules are met.
We obtained longitudinal height data of the cohort of all children born in the years 1989 and 1990 in Landgraaf and Kerkrade, located in the southern part of the Netherlands ( 481 boys, 489 girls). The total number of recorded time points between 1989 and 2001 was 14 310. The mean SDS with respect to Dutch height reference was -0.31 , consistent with known regional differences. ${ }^{2}$ In order to adjust for this, a constant of 0.31 was added to all height SDS scores. We coded all screening rules into a computer program, applied this program to the data, and calculated the percentage of children that should be referred under each rule.

Table 1 contains the results for rules I-V. No data were available for rule VI. About $6.2 \%$ of all Dutch children have a height SDS $<-2.5$ at one or more occasions between birth and 10 (boys) or 9 (girls) years. The estimated referral percentages are very high, especially for rule III $(31.5 \%)$. Combining rules $\mathrm{I}-\mathrm{V}$ results in $38.2 \%$ referrals in total. The guidelines are ambiguous as to whether rules II and III should start at birth or at age 3 (as in table 1). A start at birth results in even more dramatic referral percentages: from 5.9\% to $24.4 \%$ for rule II, and from $31.5 \%$ to $84.6 \%($ !) for rule III.

\section{COMMENT}

Strict application of the guidelines would lead to an overwhelmingly large number of false positives, would seriously impair regular practice, and create avoidable anxiety. The high referral percentages are remarkable. By definition, under rule I only $0.4 \%$ of the children have an HSDS $<-2.5$ at a given time point, whereas the estimated percentage is $6.2 \%$. These differences might be due to repeated testing and unaccounted variability. Infant length is measured about 10 times during the first two years of life. Infants are notoriously difficult to measure accurately. Variability in this period is large, and so the probability that a child has at least one HSDS $<-2.5$ is considerably larger than $0.4 \%$. In addition, the referral criteria do not account for differences in gestation, so premature births form a relatively large proportion of children short at birth. When rule I is

\begin{tabular}{|c|c|c|c|c|}
\hline Rule & Description & Criteria & Age range (years) & $\%$ referrals \\
\hline 1 & Absolute height SDS & $\mathrm{SDS}<-2.5$ & 0-10 (M), 0-9 (F) & 6.2 \\
\hline ॥ & Parental height corrected & $\begin{array}{l}\text { SDS }<-1.3 \\
\text { SDS }- \text { THSDS }<-1.3\end{array}$ & 3-10 (M), 3-9 (F) & 5.9 \\
\hline III & Deflection & $\begin{array}{l}\mathrm{T}_{2}-\mathrm{T}_{1}>1^{*} \\
\left(\mathrm{SDS}_{2}-\mathrm{SDS}_{1}\right) /\left(\mathrm{T}_{2}-\mathrm{T}_{1}\right)<-0.25\end{array}$ & 3-10 (M), 3-9 (F) & 31.5 \\
\hline IV & Slow SDS loss & $\begin{array}{l}\mathrm{T}_{2}-\mathrm{T}_{1}>1 \\
\left(\mathrm{SDS}_{2}-\mathrm{SDS}_{1}\right)<-1\end{array}$ & 3-10 (M), 3-9 (F) & 5.5 \\
\hline v & No catch-up & $\begin{array}{l}\text { SDS }_{\text {birth }}<-1.88 \\
\text { SDS }<-1.88\end{array}$ & 2-10 (M), 2-9 (F) & 1.4 \\
\hline \multirow[t]{2}{*}{$\mathrm{VI}$} & Clinical symptoms & $\begin{array}{l}\text { SDS }<-1.3 \\
\text { Disproportion or dysmorphic } \\
\text { features }\end{array}$ & 0-10 (M), 0-9 (F) & No data \\
\hline & Rules I-V combined & & & 38.2 \\
\hline
\end{tabular}

*The consensus guidelines require that at least three measurements should be taken, at least half a year apart. 
started at age 2 instead of birth, it refers to only $0.8 \%$ of the children, which is much closer to what could be expected on theoretical grounds.

A referral percentage of $38.2 \%$ corresponds to approximately 77000 children in the Netherlands each year. This is over 30 times the number expected by the consensus committee. We recommend a revision of the current screening criteria, where the development of more stringent rules is based on adequate empirical evidence.

\section{Authors' affiliations}

S van Buuren, P H Verkerk, Dept of Child Health, TNO Prevention and Health, Leiden, Netherlands

D J A Bonnemaijer-Kerckhoffs, G.G.D. Oostelijk Zuid-Limburg, Landgraaf, Netherlands
F K Grote, J M Wit, Dept of Paediatrics, Leiden University Medical Center, Leiden, Netherlands

Correspondence to: $\operatorname{Dr} \mathrm{S}$ van Buuren, TNO Prevention and Health, PO Box 2215, 2301 CE Leiden, Netherlands

Accepted 29 October 2003

\section{REFERENCES}

1 Muinck Keizer-Schrama SMPF de (representing the consensus group). Consensus 'Diagnostiek kleine lichaamslengte bij kinderen' [Consensus 'Diagnosis of short stature in childhood']. Ned Tijdschr Geneeskd 1998; 142:2519-25.

2 Fredriks AM, van Buuren S, Burgmeijer RJ, et al. Continuing positive secular growth change in The Netherlands 1955-1997. Pediatr Res 2000;47:316-23.

\section{ARCHIVIST}

\section{Blindness in the UK, 2000}

$\mathrm{n}$ developing countries diseases such as vitamin A deficiency and measles lead to preventable or treatable blindness in children and the WHO's VISION 2020 initiative,

which gives priority to children, is aimed at prevention and treatment. Now a UK survey (Jugnoo S Rahi and colleagues. Lancet 2003;362:1359-65) has shown that in developed countries the scope for prevention and treatment may be limited.

During 2000 data were gathered from UK ophthalmologists and paediatricians through the British Ophthalmological and British Paediatric Surveillance Units. A total of 439 children under 16 years of age with newly diagnosed severe visual impairment or blindness (SVI-BL) were identified. An overall cumulative incidence to age 16 years of six per 10000 children. Two thirds of the children were diagnosed in infancy. A quarter (96/408) were of low birthweight $(<250 \mathrm{~g})$ and $40 \%$ were from socially deprived families.

Diseases of the eye were not the main problem. More than three quarters (77\%) had nonophthalmic motor, sensory, or cognitive impairment, or chronic serious disease in addition to SVI/BL. Forty-four children $(10 \%)$ died within 1 year of diagnosis. Infant mortality in children with SVI/BL was 119 per 1000. The anatomical site of disease causing SVI/BL was the eye in 208 children (47\%), optic nerve in $123(28 \%)$, and visual pathways or brain in 210 $(48 \%)$. (One hundred children $(23 \%)$ had disease at more than one site.) The most important causes were retinal and macular dystrophies (14\%), optic atrophy (13\%), optic hypoplasia (12\%), hypoxic/ischaemic encephalopathy (12\%), and unknown disorder of cerebral or visual pathways $(21 \%)$. Retinopathy of prematurity caused only 13 cases $(3 \%)$. The timing of the insult was assessed as prenatal in $268(61 \%)$, perinatal or neonatal in 88 $(20 \%)$, and later or unknown in $122(28 \%)$. (Twenty-three children were allocated to more than one category.) The cause was hereditary disease in 144 children (33\%), autosomal recessive in 90 . Of the 76 children with postneonatal disease 18 had a tumour, 15 an infective cause, 12 hydrocephalus or raised intracranial pressure, 11 hypoxia/ischaemia, 9 nonaccidental injury, 3 accidental injury, and 8 systemic disorders (neurodegenerative 4, juvenile chronic arthritis 2 , diabetes 2 ). The cause was classified as definitely preventable in 14 cases (retinopathy of prematurity, rubella), possibly preventable in 19 (autosomal dominant diseases, nonaccidental or accidental injury) and treatable in 75 (cataract, glaucoma, infections, raised intracranial pressure or hydrocephalus, and other treatable causes). Three hundred and thirty-one children (75\%) had disorders not currently preventable or treatable.

Major causes of severe visual impairment or blindness in children in the UK at present are damage to cerebral/visual pathways and hereditary disease. Many children with SVI/BL have nonophthalmic problems and infant mortality is high. Only a quarter of the children have disease which is at present preventable or treatable. 